\title{
Teatro e dança no Centro de Artes da Maré - ações de contra-mundo
}

\section{Theater and dance at Maré Arts Center - counter-world actions}

Marina Henriques Coutinho ${ }^{1}$

Silvia Soter ${ }^{2}$ 


\section{Resumo}

O artigo propõe uma reflexão sobre as práticas artísticas e pedagógicas em teatro e dança desenvolvidas pelo Programa Teatro em Comunidades e pela Escola Livre de Dança da Maré no Centro de Artes da Maré. Tomando como ponto de partida as noções de "inédito-viável" e "sonho possível" (Paulo Freire, 2001a, 2001b) analisa o potencial dessas práticas e do próprio lugar em que habitam como forças de "recusa-e-criação" (John Holloway,2013) capazes de inventar um outro espaço-tempo na cidade do Rio de Janeiro.

Palavras-chave: Teatro; dança; pedagogia; comunidade; cidade

\section{Abstract}

This paper proposes a reflection on artistic and pedagogical theater and dance practices developed by Programa Teatro em Comunidades and by Escola Livre de Dança da Maré at Centro de Artes da Maré. Based on the notions of "viable-unprecedented" and "possible dream" (Paulo Freire, 2001a, 2001b), it analyses the potential of these practices and of the place they inhabit as forces of "refusal-and-creation" (John Holloway, 2013) capables of inventing another space-time in the city of Rio de Janeiro.

Keywords: Theater; dance; pedagogy; community; city

E-ISSN: 2358.6958

\footnotetext{
Profa. Dra. Universidade Federal do Estado do Rio de Janeiro (UNIRIO). marinahcoutinho@gmail.com

2 Profa. Dra. Adjunta Universidade Federal do Rio de Janeiro (UFRJ), dramaturgista na área de Dança. ssotersilvia@gmail.com
} 
Segunda-feira, 15 de outubro, dia de festa no Centro de Artes da Maré (CAM). Um grupo de mulheres prepara a mesa do café da manhã para comemorar o aniversário de 84 anos de Dona Gonçala, colega de turma das aulas de consciência corporal. Elas são alunas do professor Bruno Damião, igualmente homenageado naquele que era também o Dia do Mestre. Muitos abraços, sorrisos e fotos. A cena, que começa ao redor da mesa, se desenrola no palco em uma ciranda na qual todos dançam e cantam.

Quem frequenta o Centro de Artes da Maré sabe que é quase impossível entrar naquele galpão sem presenciar pelo menos um grupo de pessoas reunido, conversando de pé, ou sentado em roda, no palco, em ação, para uma dança, uma leitura, um canto, um toque do tambor. Como define a mareense Rosimere Viana, uma das mulheres mais assíduas das atividades no CAM: "Isso aqui é um espaço de encontro e de vida."

De fato, há um encanto naquele lugar. Por que os encontros por lá são tão especiais? Seria por que experimentamos ali o que Paulo Freire denominou como o inédito-viável? Seria por que nos sentimos ali incluídos na luta pela realização de um sonho possivel?

O Centro de Artes da Maré ocupa um enorme galpão fabril de aproximadamente 1.200 metros quadrados, subdividido em dois amplos salões. Próximo à Av. Brasil e de fácil acesso para quem mora na Maré ou em outras partes da cidade, o espaço fica na Nova Holanda, uma das 16 comunidades que compõem o Complexo de favelas da Maré. ${ }^{3}$ Como nos conta Isabella Porto ${ }^{4}$, a iniciativa para a criação do CAM nasceu do desejo e do esforço da coreógrafa e bailarina Lia Rodrigues e de Eliana Souza Silva, uma das diretoras da Redes de Desenvolvimento da Maré (Redes) ${ }^{5}$. Eliana afirma que ela e Lia "alimentaram o sonho de ter um espaço dedicado à arte na Maré. Nosso encontro se materializou na ideia de romper muros invisíveis da cidade, construindo na favela um centro de excelência" (Silva apud Porto, 2015, p.27). Desde 2008, o CAM é sede da Lia Rodrigues Cia de Danças ${ }^{6}$, que lá realiza seus ensaios diários, além de estrear e fazer as temporadas de todas as suas criações desde 2009.

A escolha de uma favela como lugar para o trabalho regular de uma companhia profissional de dança contemporânea vai ao encontro de uma nova forma de dar visibilidade às comunidades populares do Rio de Janeiro, respondendo à provocação dos geógrafos Jorge Barbosa e Jailson de Souza e Silva, que defendem a "construção de uma outra representação das favelas - para além das ausências mais visíveis" (Barbosa; Souza e Silva; Faustini, 2012, p.54). Souza e Silva acredita que a valorização da ausência e da homogeneização como elementos definidores das favelas está presente desde as primeiras formulações oficiais a respeito do fenômeno. Durante o século $X X$ e neste início do século XXI, em muitos casos, a favela é definida pelo que não é ou pelo que não tem. A identificação desses territórios como lugar de carência e de

\footnotetext{
3 O Complexo da Maré é um bairro formado por 16 comunidades situadas à margem da Baía de Guanabara, entre a Avenida Brasil e a Linha Vermelha, duas das principais vias de acesso à cidade do Rio de Janeiro. A Maré possui cerca de 132 mil habitantes distribuídos em aproximadamente 38 mil domicílios.

4 Coordenadora do Eixo de Arte e Cultura da Redes de Desenvolvimento da Maré.

5 A Redes de Desenvolvimento da Maré (Redes) é uma organização da sociedade civil que se dedica a promover a construção de uma rede de desenvolvimento sustentável, voltada para a transformação estrutural do conjunto de favelas da Maré. A Redes busca produzir conhecimento referente aos espaços populares e realizar ações com o intuito de interferir na lógica de organização da cidade e contribuir para a superação das desigualdades.
}

${ }^{6}$ A Companhia Lia Rodrigues foi fundada em 1990, no Rio de Janeiro, dirigida pela coreógrafa Lia Rodrigues. É internacionalmente conhecida. 
violência vem marcada pela visão do senso comum. Por isso, a importância do discurso alternativo nascido nesses espaços do Rio, nas últimas décadas. Lentamente, os modelos paradigmáticos que nortearam os olhares sobre as favelas estão sendo revistos e repensados, também a partir de iniciativas como a de Lia Rodrigues e seus parceiros na Maré.

Além de sede da companhia de Lia Rodrigues, o CAM abriga a Escola Livre de Dança da Maré (ELDM), desde o final de 2011, que atende gratuitamente cerca de 300 pessoas ao ano, entre crianças, adolescentes, jovens e adultos com aulas de diferentes estilos de dança. O espaço também acolhe, desde sua criação, parcerias continuadas, como é o caso do Programa Teatro em Comunidades (Unirio), e também eventuais, todas elas voltadas a consolidar o local como um espaço de estímulo a diferentes experiências estéticas, buscando a formação geral de indivíduos, o compartilhamento da experiência de criação e, sobretudo, a difusão das artes (Porto, 2015). Afinal, o que há de inédito-viável no CAM?

O inédito-viável é, na concepção de Paulo Freire, uma proposta prática de superação, pelos menos em parte, dos aspectos opressores percebidos na realidade. O risco de assumir a luta pelo inédito-viável é uma decorrência da natureza utópica, própria da consciência crítica que faz do ato de sonhar coletivamente um movimento transformador. Para Freire:

\footnotetext{
Sonhar não é apenas um ato político necessário, mas também uma conotação da forma histórico-social de estar sendo de mulheres e homens. [...] Fazendo-se e refazendo-se no processo de fazer a história, como sujeitos e objetos, mulheres e homens, virando seres de inserção no mundo e não de adaptação ao mundo, terminaram por ter no sonho também um motor da história. Não há mudança sem sonho como não há sonho sem esperança. (Freire, 2001a, p.91)
}

Sonhar coletivamente, tornar possível o impossível. A história do Centro de Artes da Maré começou a ser tecida a partir do sonho de Lia Rodrigues e de Eliana Sousa Silva de criar um espaço permanente para as artes na Maré. Hoje convivem no espaço pessoas de todas as idades, moradores de dentro e de fora da Maré, estudantes, artistas, professores, pesquisadores, gente de vários cantos da cidade, do país e até do mundo. Não há limite para a costura dessa história que se faz com muita luta.

Nossa hipótese é a de que o CAM representa uma fissura na cidade do Rio de Janeiro cuja lógica é perversa. Perversa por conta da insuportável convivência com as desigualdades sociais, da indecência do transporte público, da situação de abandono e da precarização da educação e saúde públicas, da violência, da gentrificação, da especulação imobiliária, do aumento do custo de vida etc. Cenário que, de acordo com o geógrafo David Harvey (2013), determina uma desigualdade de direitos sobre a cidade. Ou seja: quem tem dinheiro está autorizado a usufruí-la, enquanto quem não tem sobrevive em situação de extrema dificuldade.

Harvey argumenta que a ideia da cidade que nós queremos não pode estar dissociada da ideia da pessoa que nós queremos ser, "do tipo de relações sociais que buscamos, que relações com a natureza nos satisfazem mais, que estilo de vida desejamos levar, quais são nossos valores estéticos" (Harvey, 2013, p.28). O direito à cidade, afirma ele, "[é] o direito de mudar e reinventar a cidade de acordo com nossos mais profundos 
desejos, além disso é um direito mais coletivo do que individual" (Harvey, 2013, p.28).

O CAM, lugar de encontro, de convívio e de solidariedade, nos parece um exemplo de que a cidade pode ser reinventada a partir do exercício coletivo de inúmeras pessoas que realizam, naquele espaço, o inédito-viável.

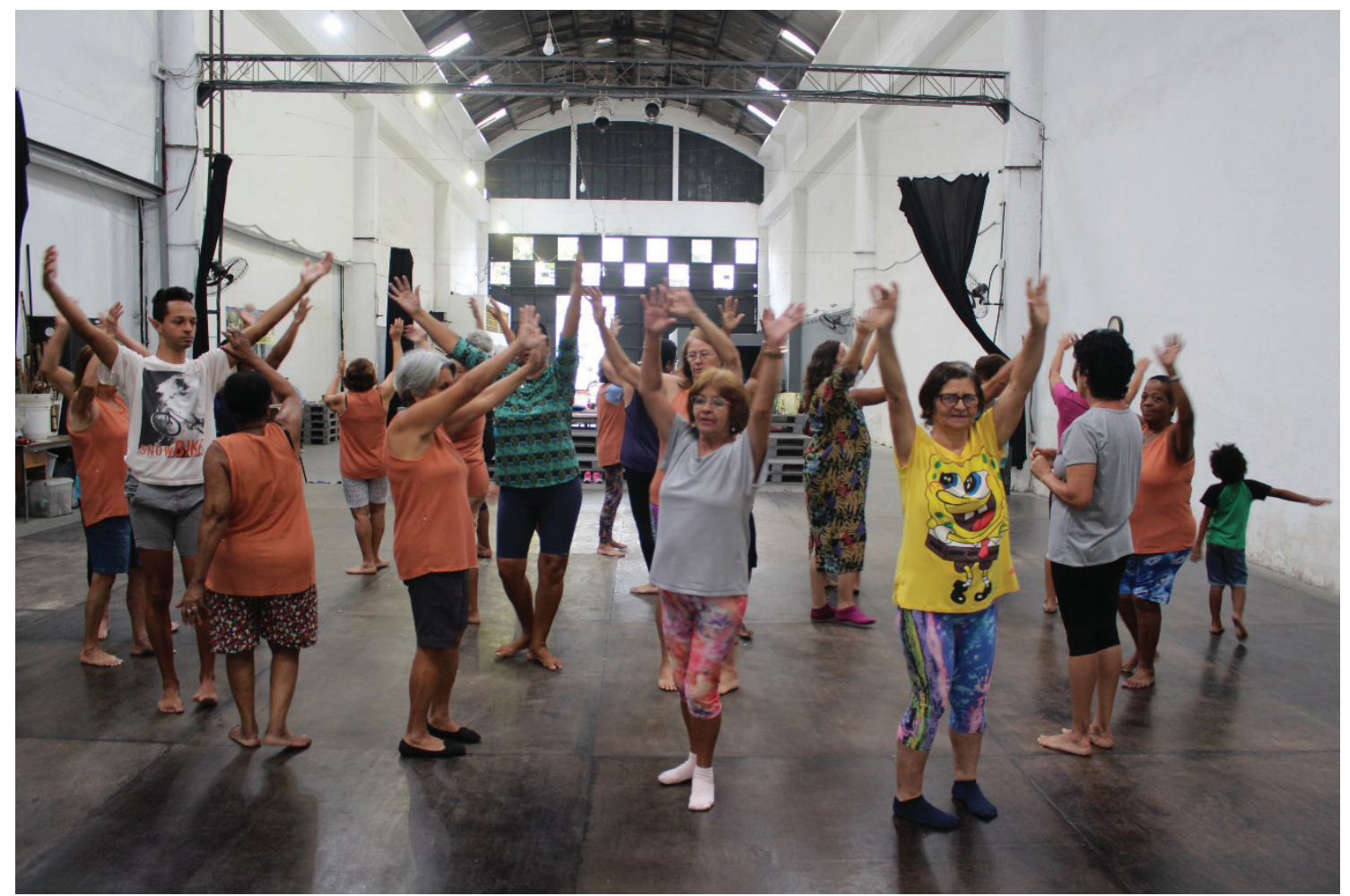

Aula de consciência corporal, CAM, out. 2018. Foto: Marina H Coutinho

As reflexões de Harvey dialogam com as de John Holloway. Em Fissurar o Capitalismo, Holloway (2013) afirma que vivemos um tempo em que frequentemente parece não haver esperança. Em que nos perguntamos "Como podemos pensar em mudar o mundo radicalmente quando isto parece ser tão impossível? O que podemos fazer?" (Holloway, 2013, p. 14). Para responder a essas questões, o autor sugere o "método da fissura", um duplo movimento de recusa-e-criação. As fissuras, segundo Holloway, começam com um não, e do não cresce uma dignidade, que é a nossa arma contra um mundo de injustiça, de guerra, de violência e de discriminação.

Para o autor a resposta para o não a este mundo quase implacável já está em desenvolvimento: fissurar o capitalismo, "rompê-lo de tantas formas quanto pudermos tentando expandir, multiplicar as fissuras, promovendo uma confluência de fissuras" (Holloway, 2013, p.14). O não, ou a recusa ao sistema que nos nega a autodeterminação e a autonomia, está apoiado, segundo Holloway, em um outro-fazer:

O Não original é uma abertura a uma atividade diferente, o limiar de um contra-mundo com uma lógica diferente e uma linguagem diferente. $\mathrm{O}$ não abre um espaço-tempo no qual tentamos viver como sujeitos, ao invés de objetos. Estes espaços ou tempos nos quais afirmamos a nossa capacidade de decidir por nós mesmos o que deveríamos fazer [...] nos quais tomamos controle de nossas próprias vidas, assumimos a responsabilidade de nossa própria humanidade. (Holloway, 2013, p.21) 
Em que medida podemos considerar o CAM e o seu conjunto de ações como o "limiar de um contra-mundo"? Como uma fissura espaço-temporal na cidade desigual e contraditória? Seria essa uma das razões para o encantamento que arrebata muitos dos que lá convivem? Afinal, se na dinâmica do mundo em que vivemos reinam o individualismo, a competição, a violência, o medo, a insegurança, ali, nos encontros promovidos pela arte, existe a tentativa de resgatar os valores mais caros à convivência humana: "camaradagem, dignidade, amorosidade, solidariedade, fraternidade, amizade, ética: todos esses nomes que contrastam com as relações mercantilizadas, monetizadas pelo capitalismo" (Holloway, 2013, p.45).

O Centro de Artes da Maré pretende recusar a lógica do sistema buscando criar espaço e momentos de fuga do mesmo. Uma observação mais cuidadosa, entretanto, evita que sejamos simplórios em considerar que tais espaços sejam totalmente autônomos (totalmente protegidos do sistema), mas, como afirma Holloway, "aspiram sê-lo" (2013, p.50). Aspiram autonomia. Segundo o autor, esses espaços estariam criando fissuras temporais e espaciais nos padrões de dominação: "Enquanto estamos juntos, nosso projeto, nossa celebração ou nossa raiva pode criar uma alteridade, uma maneira diferente de fazer e se relacionar" (Holloway, 2013, p.32).

O CAM almeja tornar a Maré um território possível para os moradores de toda a cidade, já que

a circularidade das práticas e dos imaginários culturais são indispensáveis para o enriquecimento das sociabilidades e, sobretudo, como um projeto de cidade democrática, uma vez que cultura é uma construção que permite os seres humanos interrogarem o seu cotidiano e projetarem-se na direção do futuro. (Barbosa, 2013, p.19)

Dentre as várias ações que desde 2010 foram desenvolvidas no Centro de Artes da Maré, neste artigo, abordaremos duas experiências que vêm materializando a proposta do espaço de existir como "limiar do contra-mundo", por meio das artes cênicas: o Programa Teatro em Comunidades e a Escola Livre de Dança da Maré.7 A escolha dessas duas ações se dá por terem caráter regular e permanente e pelo grande número de jovens que delas participaram nestes quase dez anos de existência.

\section{Teatro em Comunidades: viagens insólitas no CAM}

O Programa de Extensão Teatro em Comunidades habita o Centro de Artes das Maré desde 2011 como resultado da parceria firmada entre a Universidade Federal do Estado do Rio de Janeiro (Unirio) e a Redes de Desenvolvimento da Maré (Redes). ${ }^{8}$ Nos últimos oito anos, o programa tem aberto as portas do CAM todos os sábados pela

\footnotetext{
7 Além dos projetos citados neste artigo, o CAM oferece uma intensa programação de eventos artísticos, culturais e sócio-políticos. Há mostras de artes cênicas, oficinas, cineclube, exposições de arte e espetáculos de dança e teatro. Em 2017, o centro acolheu a exposição Conceição Evaristo, em parceria com o Itaú Cultural, sobre a vida da escritora e ativista. O espaço tem sido palco de ensaios e apresentações da Cia. Marginal e do Grupo Atiro, coletivos teatrais compostos por jovens atores, moradores da Maré. Desde 2017, o CAM é coordenado por Geisa Lino.

8 Idealizado e coordenado pela professora Marina Henriques Coutinho, o programa é parceiro da Redes, do CAM, do Centro Municipal de Saúde Américo Veloso (na Praia de Ramos), da Arena Carioca Dicró (na Penha) e do Observatório de Favelas. Atualmente, o programa acolhe três grupos de jovens e adultos, com cerca de 20 participantes, em cada um desses espaços. Em Ramos, o programa conta desde 2011 com a coordenação local da fonoaudióloga e professora Clarisse Lopes. Informações disponíveis em: <www.teatroemcomunidades.com.br>. Acesso em: 6 nov. 2018.
} 
manhã para receber um grupo de jovens com idades que variam de 13 a 21 anos. Além das aulas de teatro regulares, ministradas por estudantes do curso de Licenciatura em Teatro (Unirio), o programa promove ainda idas ao teatro, encontros na universidade e a "Maré de espetáculos", evento que ocorre sempre ao final do ano e que apresenta montagens de peças teatrais ao público do Centro de Artes.

A "Maré de espetáculos" é um momento muito aguardado por todos que participam do Teatro em Comunidades: pelos que fazem teatro, mas também pelos espectadores, as famílias mareenses que todos os anos lotam as plateias do CAM. Em 2017, a inspiração para a criação de uma performance teatral pelo grupo de adolescentes e licenciandos ${ }^{9}$ do Centro de Artes foi o unicórnio, animal fantástico representado pela forma de um cavalo, normalmente branco, com um grande chifre em espiral no centro da cabeça - criatura fascinante presente em diversas mitologias ao longo dos tempos. A imagem do unicórnio havia se tornado moda entre os adolescentes do mundo inteiro naquele ano. Estampada em camisetas, sapatos, roupas de dormir e esmaltes de unha, retratada com as cores do arco-íris e brilhante, a imagem do bicho mítico se tornou um símbolo de esperança, pelo menos para as crianças.

Bianca foi a menina que "viu" um unicórnio durante um jogo na aula de teatro, naquela manhã no CAM. O grupo de adolescentes estava reunido para experimentar uma oficina de dramaturgia sonora. Todos estavam deitados no chão, enquanto um músico convidado ${ }^{10}$ mexia em instrumentos de percussão. A intenção do jogo era de que a sonoridade por ele improvisada inspirasse a imaginação dos adolescentes. Ao término da atividade, todos deviam desenhar e relatar o que haviam imaginado. Foi então que Bianca contou que havia sonhado que um unicórnio surgia para salvá-la de seus problemas com a família e com a escola. Outros participantes do grupo desabafaram sobre a dificuldade de serem adolescentes e admitiram que seria ótimo se pudessem ser salvos por unicórnios.

Desta conversa delirante, proporcionada pelo jogo musical e mediada também pelos licenciandos em teatro Juliana Longuinho, Phellipe Azevedo e Diego Marques, emergiu o tema central da peça que seria montada em 2017 pelo grupo. O relato de Bianca foi seguido pelos de seus colegas e quase todos se referiam ao mesmo assunto: a adolescência. Ao perceberem o interesse do grupo por tal tema, os licenciandos decidiram colocar em prática uma "pedagogia da pergunta"11, estimulando os adolescentes a trazerem ideias que estimulassem debates e improvisações: Como foi a adolescência dos seus pais? Se você fosse escrever uma carta para você no futuro o que escreveria? Que objetos e imagens você poderia trazer para o nosso encontro que falasse sobre este seu momento de vida? Juliana lembra que para ela a chave para desenvolver o processo com o grupo foi compartilhar lembranças de sua própria adolescência: "Quando nos relacionamos com pessoas e tocamos em temas tão

\footnotetext{
9 Os estudantes de Licenciatura em Teatro ministram as aulas e trabalham sempre em duplas ou trios. Em 2017, Phellipe Azevedo, Juliana Longuinho e Diego Marques atuaram no CAM.

10 Rodrigo Souza foi convidado para ministrar um workshop sobre a construção de narrativas dos sons na cena, prática que vem sendo denominada na cena contemporânea como dramaturgia sonora.

11 Estamos nos referindo a um tipo de processo de aprendizagem mediado por perguntas que permitem investigar um tema, visando o desenvolvimento de um pensamento crítico e criativo. Tal como Paulo Freire e Antonio Faundez abordam no livro Por uma Pedagogia da pergunta, reconhecendo que todo conhecimento começa com uma pergunta, que é uma curiosidade.
} 
sensíveis para elas, acho importante que nos coloquemos no lugar delas. Acho que ao fazer isso criamos muita cumplicidade entre nós." ${ }^{12}$

Ao se confundirem com os seus educandos, como adolescentes que um dia foram, os licenciandos viveram "a abertura aos outros, a disponibilidade curiosa à vida e a seus desafios" (Freire, 2003, p.136), saberes que, segundo Paulo Freire, são necessários à prática educativa:

Viver a abertura respeitosa aos outros e, de quando em vez, de acordo com o momento, tomar a própria prática de abertura ao outro como objeto de reflexão crítica deveria fazer parte da aventura docente. A razão ética da abertura, seu fundamento político, sua referência pedagógica; a boniteza que há nela como viabilidade do diálogo. (Freire, 2003, p.136)

Esta pedagogia, cujo ponto de partida são perguntas e o mistério do encontro com o outro, exige, como observa Freire, a disponibilidade para o diálogo. Dela emerge, quase sempre, um processo que se assemelha mais a uma viagem não planejada, uma aventura. Nessas viagens abertas os licenciandos não entregam respostas prontas, mas desafiam os grupos a pensarem e a agirem sobre os temas que eles próprios elegem. A relação estabelecida entre eles e o grupo criou, como afirma Juliana, "uma empatia" que garantiu a confiança, um ambiente de pesquisa, onde os jovens se sentiam livres para expor suas experiências de vida, transformando-as em matéria cênica.

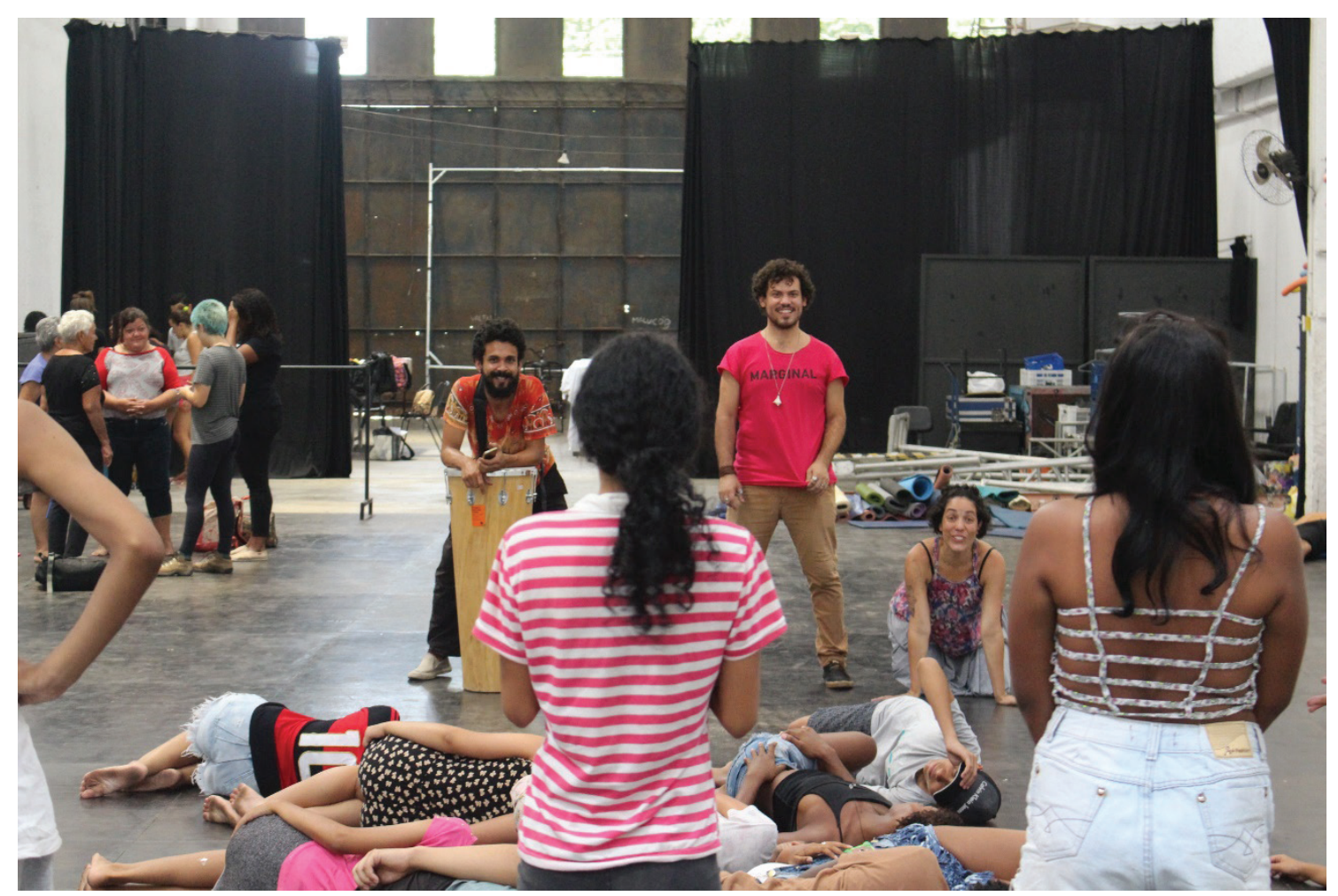

Ensaio de Unicórnio: como nasce um adolescente, CAM, 2017. Foto: Marina H Coutinho

12 Informação oral. O registro das falas dos licenciandos que aparecem neste artigo foi feito por meio de entrevistas concedidas em 2 fev. 2018. 
Após oito anos de atividades ininterruptas do Programa Teatro em Comunidades, é possível afirmar que garantir processos pedagógicos e artísticos que favoreçam a emancipação dos sujeitos envolvidos tem sido o principal desafio. De fato, um desafio em dose dupla. Isto porque o encontro entre os estudantes da universidade e os adolescentes da Maré contribui para a formação de ambas as partes. Os primeiros estudam para serem professores e portanto o convívio com grupos de educandos significa uma experiência plena de prática de ensino; já os jovens na Maré entram em contato com o teatro (universo desconhecido para a maioria deles, filhos das camadas mais pobres da sociedade) e experimentam outro modo de aprender, diferente daquele com o qual estão acostumados nas escolas formais, onde, na maioria das vezes, reina a "lógica do explicador". Como argumenta Jacques Rancière (2013, p. 24):

É o explicador que tem necessidade do incapaz, e não o contrário, é ele que constitui o incapaz como tal. [...] Antes de ser o ato do pedagogo, a explicação é o mito da pedagogia, a parábola do mundo dividido em espíritos sábios e espíritos ignorantes, espíritos maduros e imaturos, capazes e incapazes, inteligentes e bobos. [...] O mito pedagógico divide o mundo em dois. Mas, deve-se dizer, mais precisamente, que ele divide a inteligência em duas. Há segundo ele, uma inteligência inferior e uma inteligência superior.

É possível aproximar o argumento de Rancière sobre a "lógica da explicação" à crítica de Paulo Freire acerca do que chama de educação bancária. Ambas preveem a transmissão do conhecimento, uma dinâmica que "enche" os educandos de conteúdos, tendo como um dos objetivos fundamentais, de acordo com Freire $(1987,64)$,

[...] dificultar, em tudo, o pensar autêntico. [...]. Nas aulas verbalistas, nos métodos de avaliação dos conhecimentos, no chamado controle de leitura, na distância entre educador e os educandos, em tudo, há sempre uma conotação digestiva e a proibição de um pensar verdadeiro. [grifos nossos]

Não é possível pensar verdadeiro quando nos entregam respostas prontas; é preciso apostar na viagem aberta, mas o problema é que nem todos estão dispostos a correr este risco. Como teriam os licenciandos descoberto os temas mais íntimos daquele grupo, que, com tanta delicadeza, colocaram em cena? Se tivessem considerado os adolescentes imaturos ou bobos, o que teria sido daquela performance? Se tivessem sentido medo de relembrar e expor suas vivências na adolescência? Naquela relação, mestres e educandos, todos sabiam uma "infinidade de coisas":

Não há ignorante que não saiba uma infinidade de coisas, e é sobre este saber, sobre esta capacidade em ato que todo ensino deve se fundar. Instruir pode, portanto, significar duas coisas absolutamente opostas: confirmar uma incapacidade pelo próprio ato que pretende reduzi-la ou, inversamente, forçar uma capacidade que se ignora ou se denega a se reconhecer e a desenvolver todas as consequências desse reconhecimento. O primeiro ato chama-se embrutecimento e o segundo, emancipação. (Rancière, 2013, p.11) [grifos nossos]

Lado a lado com esta política, libertadora ou de emancipação, caminha também uma estética que comunica de forma poética, artística e comunitária os anseios individuais e coletivos. Afinal, qual teria sido o destino do unicórnio de Bianca se os licen- 
ciandos não tivessem desenvolvido uma ampla escuta sobre os desejos do coletivo? Teria aquele processo desaguado em um resultado que poeticamente respondia às necessidades do grupo? Teria a cena apresentado uma estética tão própria da faixa etária, do corpo, das vozes, dos ritmos, um colorido tão adolescente?

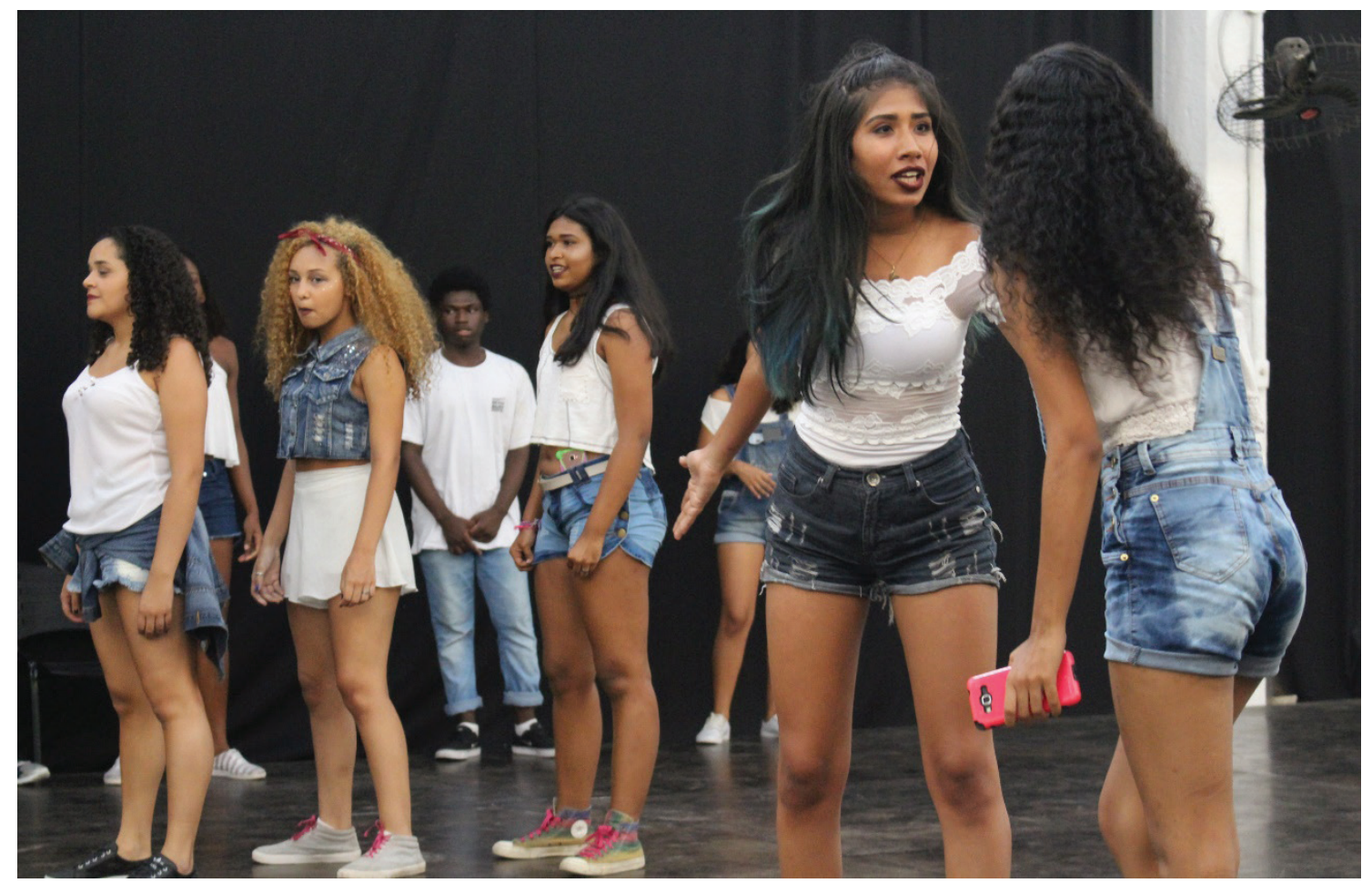

Apresentação de Unicórnio: como nasce um adolescente, CAM, 2017. Foto: Marina H. Coutinho

Os processos de criação desenvolvidos no âmbito do Programa Teatro em Comunidades buscam favorecer a emersão de uma cena própria do coletivo em questão, uma performance parida do diálogo estabelecido entre os educadores e a comunidade. Foi o que aconteceu em Unicórnio: como nasce um adolescente. Questões levantadas pelo grupo sobre os pais, a escola, as redes sociais, os crushes ${ }^{13}$, a identidade sexual e as perspectivas de futuro foram abordadas em improvisações criadas livremente pelos adolescentes ${ }^{14}$ e posteriormente transformadas em um roteiro para a performance.

Para Phellipe Azevedo, estudante da licenciatura, uma das tarefas mais difíceis do processo foi organizar a dramaturgia: "Nós não queríamos um texto decorado, queríamos que eles se guiassem pelos acontecimentos, pela ação, e deixassem as palavras fluírem, como um jogo, sem tanta preocupação em representar." Uma das cenas mais marcantes trazia a personagem da mãe ao centro do palco. Os jovens lançavam perguntas a ela, que sempre respondia com um "não". Até que as perguntas ganhavam um tom mais sério, tratando do tema da violência na favela: "Mãe, eu posso sair na rua sem ser revistada pela polícia? Mãe, eu posso me esconder na hora do tiroteio? Mãe, eu posso ficar mais de três dias sem ir à escola porque está acontecendo operação po-

\footnotetext{
13 Crush é uma gíria que tem sido usada pelos jovens brasileiros para se referir a alguém por quem estão apaixonados.

14 Anderson Oliveira, Deyvilly Eduarda, Natália Brambila, Bianca Alcantara, Leny de Aquino, Julie Oliveira, Victória Veiga, Gaby Santos, Ariane Macedo, Pablo Batista, Matheus Benny, Diego Amarante, John Damasia, Juliana Martin e Marianne Costa.
} 
licial?" A mãe passa a responder "sim" para todas elas. Este é o momento de Unicórnio em que nos deparamos com algo que faz parte da realidade de vida dos moradores do Complexo da Maré: a violência cotidiana, consequência das disputas territoriais pelas facções do tráfico de drogas e dos conflitos com a polícia. ${ }^{15}$

Os conteúdos abordados pelas cenas da peça e seu processo de criação foram atravessados por fundamentos pedagógicos e semelhantes escolhas formais presentes na maioria dos resultados de montagens do Teatro em Comunidades. $O$ uso de depoimentos, relatos ou cartas dentro dos processos e também na cena revela a tendência de uma parcela considerável das práticas artísticas contemporâneas que vêm transgredindo algumas noções mais rígidas do que entendemos como o resultado de um espetáculo. Por exemplo: a recusa, a interpretação de textos dramáticos prontos e a caracterização de personagens, a opção pelo uso de fragmentos literários ou escritas próprias dos participantes, uma textura de atuação que mais se aproxima do que eles são na vida real, "a proliferação de performances cada vez mais autobiográficas e a inclusão de não-atores em cenas disjuntas" (Fernandes, 2013, p.3) são elementos perceptíveis nos processos e nas teatralidades episódicas, inacabadas na montagem aqui em questão. Não seria arriscado afirmar que, mais do que como atores, os adolescentes agiam como performers.

Phellipe e Juliana comentam que a intenção deles era criar com os adolescentes uma presença cênica muito próxima da presença deles na vida: "Claro que isso não seria totalmente possível, porque sempre há a mediação do simbólico, da ficção, mas nós não queríamos a representação de personagens, queríamos que eles mesmos aparecessem em cena." Juliana observa que o envolvimento do grupo no processo foi tão grande que era como se eles estivessem dizendo: "Olha, mãe, esse sou eu." Esse recado não estava apenas no palco, mas também na exposição Afetos compartilhados, que o grupo criou a partir de fotografias, colagens, cartas e objetos que serviram como estímulos para a criação da performance e que eles quiseram mostrar aos espectadores nos dias de apresentação. ${ }^{16}$

No último momento da peça, os adolescentes olhavam para a plateia em busca de seu unicórnio. Um texto era lido em off:

Eu sentia que estava perdida.

Eu dançava, dançava pra juntar meus pedaços.

Umas cores iam se formando... umas cores fortes, lindas...

Eu fui pro céu e eu via tudo que estava acontecendo.

Esse sonho foi bem louco.

Na verdade eu não estou bem com a minha família.

Eu queria alguém comigo aqui.

$\mathrm{Eu}$ estou com um pressentimento ruim a semana toda.

Mas um unicórnio me salvou.

\footnotetext{
${ }_{15}$ A Maré vive um histórico de abandono do poder público. Tal abandono aproxima os jovens da experiência vivida pelos demais moradores das periferias urbanas brasileiras, que têm seu cotidiano marcado pela combinação de inúmeras vulnerabilidades: baixa escolaridade, convívio com grupos criminosos, conflitos armados frequentes e preconceito. O cotidiano do morador de favelas no Rio de Janeiro é marcado pela falta de políticas públicas de segurança. Na Maré ocorrem constantes enfrentamentos entre policiais e traficantes, mas também entre diferentes gangues de tráfico de drogas, e até mesmo invasões a casas de moradores por parte de policiais, num desrespeito evidente aos direitos humanos.

16 As peças foram apresentadas no Centro de Artes da Maré, no CMS Américo Veloso e no palco principal da Escola de Teatro da Unirio em 2 dez. 2017 e 16 dez. 2017. Um minidocumentário sobre a Maré de espetáculos 2017 está disponível em:

<https://www.youtube.com/watch?v=yb1ALqOV10c\&t=171s>. Acesso em: 6 nov. 2018.
} 
Muitas mães e pais foram convidados a subir ao palco - unicórnios da vida real. Ao término todos receberam aplausos. As aventuras de Unicórnio: como nasce um adolescente haviam chegado ao fim. Mais um grupo completava um ano de atividades no programa de extensão Teatro em Comunidades.

Como afirma Tim Prentki, a arte significa "comunicar o que a vida normalmente esconde da gente, levar-nos a lugares de surpresa, do choque, do maravilhamento, expelindo-nos das zonas do hábito e do conforto para mudar nossas noções do que somos e do que podemos ser" (Prentki, 2009, p.25). Assim, todos eles, "para enfrentar um mundo de injustiça, violência e discriminação" (Holloway, 2013, p.7), embarcaram em viagens insólitas; montados em cavalos alados, visitaram ao mesmo tempo recantos misteriosos do real e da ficção, descobriram formas inusitadas do sentir e do pensar autênticos.

\section{A Escola Livre de Dança da Maré: ELDM}

Criada pela Lia Rodrigues Companhia de Danças e por Silvia Soter em parceria com a Redes de Desenvolvimento da Maré, a Escola Livre de Dança da Maré abriu as portas em outubro de 2011 e se constituiu como um conjunto de atividades integradas em torno do ensino da dança. ${ }^{17}$ Desde sua criação, acolhe diretamente crianças, adolescentes e adultos das 16 comunidades que formam a Maré e de outros bairros do Rio de Janeiro e da região metropolitana. Mais de 600 pessoas se inscreveram desde sua abertura; em 2018, ela conta com aproximadamente 300 alunos ativos. A ELDM integra prática de dança, formação de artistas e de público e atividades socioeducativas. Suas atividades se estruturam em dois eixos, organizados como núcleos.

O Núcleo 1 reúne oficinas de dança de diferentes estilos e de outras práticas corporais. A ELDM também investe na formação intensiva em dança de um grupo de 20 jovens, em média, de 16 a 25 anos, o "Núcleo 2", principal elo entre a Lia Rodrigues Companhia de Danças e a ELDM. O grupo participa de uma formação intensiva de dança que consiste em quatro horas de aulas diárias de atividades, de segunda a sexta, sob a supervisão pedagógica de Silvia Soter, a coordenação de Gabriel Lima e a direção artística de Lia Rodrigues, auxiliada por seus bailarinos, com a participação de professores convidados. Essa formação não é "diplomante", não há um tempo pré-determinado para sua conclusão ou uma certificação oficial ao final da experiência. Seu objetivo maior é expandir o horizonte de possibilidades desses jovens por meio da dança, permitindo que a mesma se torne até uma escolha profissional possível.

Por meio das ações do Núcleo 1, a escola busca democratizar o acesso aos cursos de dança para os habitantes da Maré e de outras partes da cidade, oferecendo cursos gratuitos de estilos diferentes (hip-hop, dança de salão, dança contemporânea, danças afro-brasileiras, balé clássico e consciência corporal). É importante ressaltar que no Brasil praticamente não há aulas de dança na educação básica e que são poucas as escolas públicas e conservatórios de dança de acesso gratuito ou com preços acessíveis, fazendo com que aulas de dança sejam acessíveis apenas aos que

\footnotetext{
17 Mais informações a respeito da ELDM disponíveis em <https://www.youtube.com/watch?v=YuqVOCZBtiA>.Acesso em: 7 nov. 2018.
} 
podem pagar os cursos livres, as dita academias de dança. A ELDM é também um lugar de encontro, como destaca Gabriel Lima:

\begin{abstract}
Aqui o nosso maior objetivo não é formar bailarinos. Até porque somos uma escola livre de dança. No Núcleo 2 é diferente, mas nas outras aulas o objetivo é socializar através da dança. A escola existe para ser um espaço de encontros, onde as pessoas possam estar, acessar outras coisas, e isso fica muito nítido com a turma de senhoras. ${ }^{18}$ [grifos nossos $]^{19}$
\end{abstract}

Já a formação mais recente do Núcleo 2 conta com 22 alunos que entraram por audição em setembro de 2018. Estes jovens, a maioria de famílias de baixa renda, recebem uma pequena ajuda de custo para cobrir o transporte e para que possam se dedicar à dança por tantas horas por semana. Em dezembro de 2018, o grupo de dez jovens que estiveram juntos no Núcleo 2 desde 2011 encerrarão sua participação como alunos. Alguns pretendem seguir ligados à ELDM como professores. Todos os dez jovens ingressaram nos cursos superiores de dança da Universidade Federal do Rio de Janeiro (UFRJ) nos últimos anos, enquanto frequentavam a ELDM. Para a vida desses jovens, a dança tornou-se central.

A ELDM é mantida com recursos esparsos e descontínuos, por meio de leis de incentivo à cultura e parcerias estabelecidas com a Redes da Maré, com a Lia Rodrigues Companhia de Danças e com fundações estrangeiras. A falta de garantia de financiamento perene e os desafios de desenvolver um trabalho de arte na Maré, território também marcado pela falta de segurança e habitado por famílias de baixa renda, obriga constantemente a coordenação a avaliar e repensar suas estratégias de ação. Lia Rodrigues fala de uma metodologia mutante, enfatizando que adaptar-se aos limites, às possibilidades e às oportunidades que se apresentam a manter uma escola de dança na Maré é condição para lá permanecer e garantir que o trabalho junto aos jovens continue, num lugar que muda o tempo todo. Lia Rodrigues acredita que a formação de um artista se dá em tempo indeterminado e essa sua crença está à base da Escola Livre de Dança da Maré. A coreógrafa diz:

$\mathrm{Eu}$ gostaria que a escola fosse um lugar assim, fosse um lugar eterno e que as pessoas ficam o tempo que elas acham necessário para aqueles projetos. [...]. Talvez seja essa metodologia mutante, que seja uma metodologia também que não tenha um tempo preciso. Porque as pessoas podem entrar e sair. [...]. Porque eu acho que esse desejo de formatar em três anos, em quatro anos, não se adequa à nossa realidade. E também não se adequa ao que a gente pensa, eu acho. Eu não acredito nessa escola, nem pros nossos filhos, eu acredito. Acho que devia ser uma coisa, assim, que você passa, viaja um tempo com isso, aí, vai... aí, a escola também... de repente, a escola que tá indo por aqui deseja ir pra lá, acho bom. (Rodrigues apud Soter; Braga, 2018)

Desde 2011, se adaptando às possibilidades concretas e levando em conta os interesses e necessidades dos alunos, a formação intensiva em dança para o Núcleo 2 combina aulas de dança contemporânea, de balé clássico e de outras práticas corporais com

\footnotetext{
18 Em 2015 foi realizado um levantamento do perfil dos alunos e constatou-se que $25 \%$ dos alunos da Escola (Núcleo 1) eram compostos de mulheres de mais de 51 anos. Elas frequentam as diferentes aulas no Núcleo 1, mais concentradas nas aulas de consciência corporal e de yoga.

19 Informação oral. O registro da fala de Gabriel Lima neste artigo foi feito por meio de entrevista concedida em 2 jun. 2018. Mais informações disponíveis em <https://www.youtube.com/watch?v=A7Q40PDscjl>. Acesso em: 7 nov. 2018.
} 
professores regulares e também com profissionais convidados para intervenções pontuais, alguns destes estrangeiros. Além das aulas de dança, o grupo se reúne mensalmente com uma equipe de psicólogas para rodas de conversa, mediadas por Rosana Rapizo 20 . A programação das atividades, decidida pela coordenação pedagógica e artística da escola, é planejada em ciclos que não ultrapassam quatro meses. Desde o início dos anos 2000, Lia Rodrigues vem sublinhando a dimensão formativa de sua companhia de dança. Muitos artistas que nesta ingressaram jovens e com pouca experiência, após alguns anos de trabalho na companhia passaram a desenvolver seus próprios trabalhos autorais autônomos (Pavlova; Soter, 2017, p.269). Inspirada nessa experiência, a proposta pedagógica da ELDM associa formação e criação artística.

A Lia Rodrigues Companhia de Danças esteve à frente de três projetos de criação junto aos estudantes do Núcleo 2. De setembro de 2012 a abril de 2013, o grupo de estudantes fez uma imersão no repertório da companhia para realizar uma peça-exercício, a partir da obra Aquilo de que somos feitos, de 2000. Em abril de 2003, estrearam Exercício $M$, de movimento e de Maré, ${ }^{21}$ que foi apresentada em universidades, escolas de educação básica e no Centro de Artes da Maré. Os jovens, sob orientação de Lia Rodrigues e dos artistas de sua companhia, aprenderam a segunda parte da peça e criaram solos e duos, usando estratégias de criação da companhia como base.

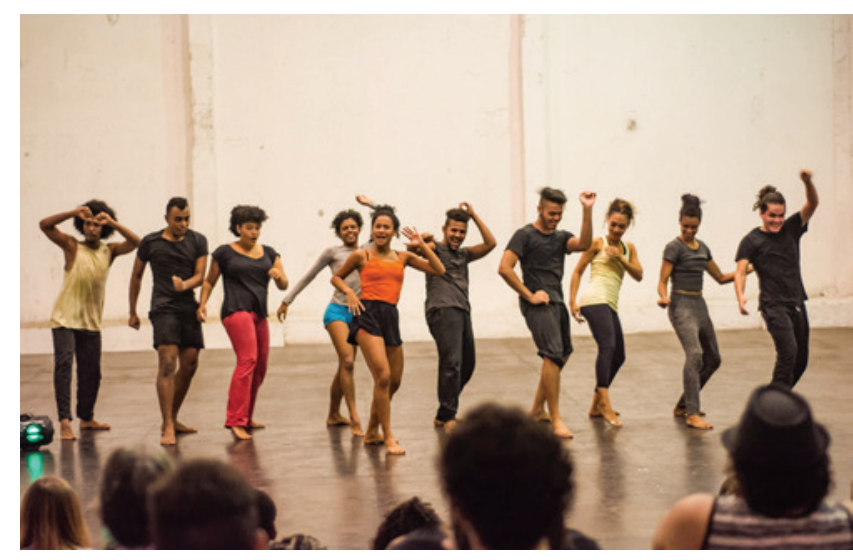

Cena na peça Exercício P, de Piracema e Pororoca, de Lia Rodrigues, com os estudantes do Núcleo 2, em 2017. Foto: Douglas Lopes

Em 2017, uma nova aproximação entre a companhia e o Núcleo 2 teve como fruto a peça Exercício $P$, de Piracema e Pororoca, outra experiência de mergulhos nas práticas de criação da companhia e em seu repertório. De setembro de 2017 a março de 2018, aos jovens foi ensinada a peça May $B$, da coreógrafa francesa Maguy Marin, como eixo do projeto "De Ste-Foy à Rio: May B à la Maré, une fraternité", parceria de Lia Rodrigues com a coreógrafa francesa. ${ }^{22}$ Os jovens realizaram uma turnê de dois meses na França com o espetáculo.

\footnotetext{
20 Sobre a experiência das rodas de conversa, ver: Rapizo, Rosana Espaço de Conversas com jovens na Maré: dançando entre o "eu" e o "nós". In: Marilene Grandesso. Colaboração e Diálogo: Aportes teóricos e possibilidades práticas. Curitiba: CRV, 2018, p. 521-540.

21 Mais informações disponíveis em <https://www.youtube.com/watch?v=HrOd-HwJc6l>. Acesso em: 7 nov. 2018.

22 Para mais informações sobre o projeto, ver Faire Danser le monde. Disponível em: <https://www.youtube.com/watch?v=SMvm41_x79g>. Acesso: 4 nov. 2018
} 
Segundo Lia Rodrigues, ao participar de um processo de montagem e criação em grupo, os jovens em formação desenvolvem importantes competências:

Você aprende milhares de coisas, [aprende a] trabalhar em grupo. Quando você trabalha em grupo, é que nem democracia, você tem que abrir mão pelo grupo, pelo outro, fazer uma combinação do seu desejo com o do outro, que é um trabalho que exige que você esteja perto, fazendo ao mesmo tempo, porém diferente, sem pisar no pé do outro. É bem isso. E ainda é uma escrita totalmente estruturada, mas dentro dessa estrutura você também aprende como que ter liberdade dentro de uma estrutura. O que eu acho muito legal. (Rodrigues apud Soter; Braga, 2018)

Além de Lia Rodrigues e de sua companhia, a ELDM vem acolhendo oficinas e residências de outros artistas. A rede solidária de instituições, artistas e professores nacionais e estrangeiros ${ }^{23}$ que se criou em torno do projeto também tem sido fundamental para ampliar as possibilidades de trocas e práticas para os jovens alunos. A escola estabeleceu parcerias com outros centros internacionais de formação em dança, por meio da rede de contatos que a coreógrafa construiu ao longo dos anos. Alguns intercâmbios internacionais se destacaram. Em 2013, os jovens do Núcleo 2 estiveram em intercâmbio com jovens da Académie de Danse das Écoles Municipales Artistiques, de Vitry-sur-Seine, França. Em 2016 e 2017, dez estudantes (cinco a cada ano) participaram do Camping, um importante encontro de escolas e formações de dança no Centre National de la Danse CND, em Pantin, na França.

Em dezembro de 2016, os dez alunos participaram da primeira fase do intercâmbio com o Bachelor Danse de La Manufacture, em Lausanne, na Suíça. Em abril de 2017, os estudantes do terceiro ano do Bachelor Danse fizeram uma residência de um mês na Escola Livre de Dança da Maré. Também em 2016, quatro integrantes do Núcleo 2 foram selecionados para a audição para a turma de 2016-2019 de formação em dança contemporânea da P.A.R.T.S, em Bruxelas, na Bélgica. No final da seleção, Gustavo Gláuber e Rafael Galdino ficaram entre os 44 candidatos escolhidos e ingressaram na escola belga, onde estão até hoje. A ampliação dos horizontes de possibilidades que o projeto permite aos seus participantes é destacada na fala do estudante do Núcleo 2, Marllon Araújo:

\begin{abstract}
Me sinto privilegiado de estar nessa formação tão rica de experiências, pois no Núcleo 2 eu encontro um lugar onde eu posso me expressar e me encontrar com o outro, seja professor, aluno... continente, país. A troca cultural do projeto de intercâmbio, que essa formação me proporcionou em dezembro de 2016 e abril desse ano com a Escola Manufacture mudou meu olhar para o mundo e me mostrou que as fronteiras foram feitas pra serem atravessadas, independente das realidades... o mundo é nosso! [...] O encontro com a escola "Manufacture" de Lausanne, Suíça, foi a experiência que mais me atravessou e é o que carrego mais presente no momento. Digo isso diante do choque da realidade cultural e principalmente de classe social. E no meio de toda essa divergência, dos dois países, nos encontramos para DANÇAR a mesma língua. Dançamos, as divergências se completaram e a troca aconteceu. ${ }^{24}$
\end{abstract}

\footnotetext{
23 Em 2016, o Núcleo 2 teve aulas e participou de oficinas com a dupla de artistas multimídia Carolyne Badouin e Cyril Hernandez, que apresentou, em sete encontros, um estudo sobre o tema Da tarde do Fauno (1912) até a Sagração da Primavera (1913), um mergulho nas obras primas de Nijinski. Além disso, tiveram aulas com o coreógrafo francês Fabrice Ramalingom, com as artistas brasileiras Dani Lima e Andréa Jabor e ainda participaram da remontagem da peça Cribles (2009), de Emmanuelle Huynh, sob orientação da própria. Além, evidentemente, do trabalho com os artistas da Lia Rodrigues Companhia de Danças.

24 Informação oral. Registro de entrevista concedida a Isabella Porto em agosto de 2018.
} 
A aposta em intercâmbios e trocas entre artistas e estudantes do Brasil e de outros países é uma estratégia adotada pela ELDM para tentar romper com a cisão entre diferentes espaços da cidade e de seus moradores, entre os moradores da Maré e os moradores de outros lugares. O Centro de Artes da Maré tem se constituído como laboratório de encontros, um espaço na cidade do Rio de Janeiro para que moradores de seus diferentes bairros e de outras partes do mundo se encontrem e colaborem para projetos comuns em torno das artes cênicas, do teatro e da dança.

Vivemos um tempo difícil. É verdade que nos sentimos nas "mãos de forças ruins", como escreveu Bertolt Brecht $\left(1986\right.$, p.257) em um poema tragicamente atual ${ }^{25}$, mas o que seria de nós se não pudéssemos nos inspirar no colorido dos unicórnios ou nos movimentos dos bailarinos para acreditar que, como um lampejo ou um raio, nossas ações acendem um mundo diferente, talvez apenas por alguns instantes ou algumas horas? "A imagem do mundo que podemos criar (e criamos). O mundo que ainda não existe, se mostra como um mundo que existe como ainda-não" (Holloway, 2013, p.33). É no corpo a corpo, na criação coletiva em teatro e em dança, no convívio em grupo sem pisar no pé do outro que se produz o maravilhamento que nos afasta de nossas zonas de hábito, fazendo que, como lembra Prentki, possamos nos abrir a outras possibilidades de ser e existir.

Essa força que nos encanta é percebida no Centro de Artes da Maré, pedaço de chão do Rio de Janeiro onde a arte e a convivência entre as pessoas parecem nos deixar mais próximos da realização do sonho possível, porém nada fácil, da invenção democrática de nossa sociedade (Freire, 2001a).

\section{Referências}

BARBOSA, Jorge Luiz. Solo cultural da cidade. In: BARBOSA, Jorge Luiz; GONÇALVES DIAS, Caio (org.). Solos culturais. Rio de Janeiro: Observatório de Favelas, 2013.

BRECHT, Bertolt. Poemas 1913-1956. Trad. Paulo Cesar Souza. São Paulo: Brasiliense, 1986.

FERNANDES, Silvia. Experiências do real no teatro. Revista Sala Preta (PPGAC/USP), São Paulo, v. 13, p. 3-13, 2013.

FREIRE, Paulo. Pedagogia da autonomia. Saberes necessários à prática educativa. São Paulo: Paz e Terra, 2003.

FREIRE, Paulo. Pedagogia da Esperança. Um reencontro com a Pedagogia do Oprimido. Rio de Janeiro: Paz e Terra, 2001a.

FREIRE, Paulo. Pedagogia dos Sonhos Possíveis. Org. Ana Maria Araújo Freire. São Paulo: UNESP, 2001b.

25 Poema "Sobre o julgamento", escrito no período de 1938-1941, como consta no livro com coletânea de poemas de Brecht (1986). 
FREIRE, Paulo. Pedagogia do Oprimido. Rio de Janeiro: Paz e Terra, 1987.

HARVEY, David. A liberdade da cidade. In: HARVEY, David et al. Cidades rebeldes, passe livre e as manifestações que tomaram as ruas do Brasil. São Paulo: Boitempo: 2013, p. 27-34.

HOLLOWAY, John. Fissurar o capitalismo. São Paulo: Publisher, 2013.

PORTO, Isabella. Centro de Artes da Maré. In: COUTINHO, Marina Henriques (org.). Programa Teatro em Comunidades. Rio de Janeiro: Unirio, 2015.

PRENTKI, Tim. Contranarrativa. Ser ou não ser: Esta não é a questão. In: NOGUEIRA, Marcia Pompeo (org.). Teatro na comunidade, interações, dilemas e possibilidades. Florianópolis: Ed. UDESC, 2009, p. 13-36.

RANCIĖRE, Jacques. O mestre ignorante. Cinco lições sobre a emancipação intelectual. Belo Horizonte: Autêntica, 2013.

SOTER, Silvia; BRAGA, Paola Secchin. Artistes en situation pédagogique: Savoirs artistiques et savoirs pédagogiques dans les pratiques de Thomas Hauert et Lia Rodrigues. Rapport Scientifique. Lausanne: Recherche lLa Manufacture,Lausanne, 2018. 45 p. Disponível em: <http://www.manufacture.ch/download/docs/zkx3wpr9.pdf/Artistes\%20en\%20 situation\%20pedagogique-Rapport\%20scientifique.pdf >. Acesso em: 6 nov. 2018.

SOTER, Silvia; PAVLOVA, Adriana. Escola Livre de Dança da Maré in Rio de Janeiro: a ground to share. In: BUTTERWORTH, Joanne; WILDSCHUT, Liesbeth. Contemporary Choreography: A Critical Reader. New York/Londres: Routledge, 2017, p. 268-278.

SOUZA E SILVA, Jailson; BARBOSA, Jorge Luiz; FAUSTINI, Marcus. O novo carioca. Rio de Janeiro: Mórula, 2012.

Recebido em: 12/11/2018 Aprovado em: 21/01/2019 